\title{
Does the Order of Information Affect Investors' Investment Decisions? Experimental Investigation
}

\author{
Riyadi Aprayuda ${ }^{1 *}$, Fauzan Misra², and Rayna Kartika ${ }^{3}$
}

\begin{abstract}
:
Research aims: This study examines the order of information's effect according to the Belief Adjustment Model. In particular, this study investigates the effect of the direction of the order and the pattern of presenting information in making investment decisions.
\end{abstract}

\section{AFFILIATION:}

${ }^{1}$ Department of Accounting,

Faculty of Economics and Business, Universitas Muhammadiyah Riau, Riau, Indonesia

2,3 Department of Accounting, Faculty of Economics, Universitas Andalas, West Sumatra, Indonesia

\section{*CORRESPONDENCE:}

riyadiaprayuda@gmail.com

THIS ARTICLE IS AVAILABLE IN:

http://journal.umy.ac.id/index.php/ai

DOI: 10.18196/jai.v22i1.9965

\section{CITATION:}

Aprayuda, R., Misra, F., \& Kartika, R. (2021). Does the order of information affect investors' investment decisions?

Experimental investigation. Journal of Accounting and Investment, 22(1), 150-172.

\section{ARTICLE HISTORY}

Received:

07 Oct 2020

Revised:

24 Nov 2020

23 Dec 2020

05 Jan 2021

Accepted:

06 Jan 2021

Design/Methodology/Approach: The research applied an experimental method with web-based instruments using a $2 \times 2$ factorial design between subjects, involving 65 investors.

Research findings: The investors' investment valuation who received negative to positive information sequence direction was higher than the investors who received positive to negative information direction. Furthermore, there was an order effect in the form of recency on investors who received a partial presentation pattern. Meanwhile, investors who received a simultaneous pattern did not show an order effect in their assessment. These findings underline that the simultaneous pattern could reduce the order effect, so that investors need to generalize the information as a whole to avoid this bias.

Theoretical contribution/Originality: This study extends the investigation of investment decisions using a long sequence of information perspectives and more varied types of information (e.g., financial information, corporate governance, and industry sectoral information that has an impact on company conditions) in making investment decisions on the belief adjustment model.

Practitioner/Policy implication: Companies must maintain the direction of the order and the presentation patterns when issuing company information to maintain the quality of investors' decisions and avoid the risk of volatility in company shares.

Research limitation/Implication: Participants who joined this research were active investors but had not yet had a comprehensive experience.

Keywords: Investment Decision; Order Effect; Recency

\section{Introduction}

On an ongoing basis, information disclosed by the company will be quickly integrated into the company's share price in the capital market. The dissemination of information is currently supported by the existence of the internet and social media used by investors due to the cost benefits and the easiness of accessing information (Sofyan, Putra, \& Aprayuda, 2020). 
However, information published by companies tends to have negative and positive directions close to each other (Daigle, Pinsker, \& Pitre, 2015). Graham, Harvey, and Rajgopal (2005) have proved that two-thirds of 400 Chief Financial Officers (CFO) released good news and bad news separately, but close to each other. When investors evaluate evidence and information with the direction of bad news information followed by good news or vice versa, heuristic bias will occur in their judgment (Bazerman, Giuliano, \& Appelman, 1984). It happens because individuals have limited rationality when they want to make decisions (Bazerman, 1994). Alvia and Sulistiwan (2010) argued that the causes of heuristic bias, one of which, is the order effect, in which investors do not make judgments based on the information's substance available but based on the order in which the information is presented or the evidence itself.

Hogarth and Einhorn (1992) describe the concept of Belief Adjustment theory, which implies that the sensitivity of a person's behavior tends to play a large role in decision making. Belief adjustment predicts that the order effect will occur when individuals process information due to the interaction between information processing strategies and task characteristics. Belief adjustment assumes that when individuals receive pieces of information in a particular direction and pattern, they will make adjustments in assessing the information.

Tuttle, Coller, and Burton (1997) stated that individuals in the stock market tend to be biased when assessing information in a specific order. When information is in a positive to negative order, the individual tends to be biased to give a decreasing assessment; whereas, in a condition where the order is negative to positive, the individual tends to give an increased assessment. It explains that investors are vulnerable to the effect of the order of information, especially from the direction of the last information they receive. In line with this opinion, Alvia and Sulistiwan (2010), Almilia, Hartono, Supriyadi and Nahartyo (2013), Almilia and Supriyadi (2013), Hanafi (2017), and Nisa (2017) have found empirical evidence that there is a sequential effect in the form of a recency effect in individuals' investment decisions when they evaluate short information series information. It suggests that when individuals make investment decisions by evaluating short series of information, they are more affected by the order effect, and they tend to be more sensitive to newer information than to the initial information (recency).

Alvia and Sulistiwan (2010), Almilia et al. (2013), Almilia and Supriyadi (2013), Hanafi (2017), and Nisa (2017) have investigated the effect of the order of information on investment decisions using a short series of information. However, the small number of information series presented in previous research did not adequately describe the information received by investors in the stock market. It is evidenced by Alattar and AlKhater's (2007) findings, which described that practically, investors in the market make the use of information from various sources, such as balance sheets, auditor reports, cash flow statements, income statements, and financial statement notes as the most crucial part. Also, they found evidence that investors consider government publications and newspapers, magazines, and journals to be crucial, useful, and easily accessible sources of information. Besides, Deegan and Rankin (1997) elucidated that investors in the stock market would be exposed to much more complex and diverse market 
information. Thus, it is necessary to investigate the order's effect of investment decisions in a longer and more diverse series of information to describe the information received by investors in the stock market.

Moreover, Daigle et al. (2015) have explored the order impact on the revision of nonprofessional investor confidence when presenting a long series of information in the manipulation of market conditions. Their research findings are in line with the preliminary findings of Pinsker (2011), which stated that there is a sequential effect in the form of recency effects in the judgment of non-professional investors when they evaluate information that is in the direction of good news followed by bad news or vice versa, in which the news is displayed in a sequential or simultaneous pattern. However, with the same research concept, Rafay and Farid (2018) uncovered evidence that there is an order effect in the form of a primacy effect when investors evaluate information simultaneously. They emphasized that investors are vulnerable to primacy effects even though the information is believed to be fair, objective, and useful for decision making. In particular, they stated that the order of information consciously influenced investors' decisions by exploiting human cognition limitations. On the other hand, Rofiyah and Almilia (2017) did not find an order effect in investment decisions on the simultaneous presentation pattern when long information series was presented.

The empirical evidence proven by previous researchers is either inconsistent between researchers or the theoretical perspective of the Belief Adjustment Model's prediction (Hogarth \& Einhorn, 1992), which implies that there will be an order effect in the form of a primacy effect when individuals evaluate long series of information. It occurs because the length of the information series causes individuals to be less sensitive to newer information, making their beliefs consistent with previous information. Therefore, there are still contradictions between the theoretical and empirical results that must be investigated further.

Previous research that examined investment decisions using a long series of information is still limited to only using one type of information variation, such as voluntary disclosure (Daigle et al., 2015; Pinsker, 2011), shariah supervisory board report (Farid, 2017), and corporate social responsibility (Rofiyah \& Almilia, 2017). Alattar and AlKhater's (2007) finding emphasized that investors use many types of information, while Deegan and Rankin (1997) stated that investors in the stock market face high information complexity. Thus, one variation of information is insufficient to describe the information received by investors in the stock market. Therefore, this study expands the investigation of investment decisions using the perspective of a long sequence of information with more varied types of information, such as financial information, corporate governance, and industry sectoral information, which impact company conditions.

Besides, this study also considers risk preference as a covariate because it influences a person's decisions (Gardner \& Steinberg, 2005; Engelman \& Tamir, 2009). Specifically, this study's objectives are (1) to examine the main effect between the direction of the information order and investment decisions, (2) to test the main effect between 
information presentation patterns and investment decisions, and (3) to investigate the interaction effect and the simple effect between patterns of sequential and simultaneous presentation of information, describing how the order effect in investor decisions occurs in each pattern.

Research on the effect of the order of information on investment decisions based on belief adjustment has been carried out, for example, by Pinsker (2007), Alvia and Sulistiwan (2010), Almilia et al. (2013), Almilia and Supriyadi (2013), Hanafi (2017), and Nisa (2017). Most of these previous studies used a series of short series of information. Belief adjustment research employing a long series of information is still scarce. As for studies that have tested a long series of information sets, for example, are Pinsker (2011), Daigle et al. (2015), Rafay and Farid (2018), and Rofiyah and Almilia (2017). However, the research conducted has only tested one type of variation in the information. It is why this study, with a long series of information domains, utilized a more diverse variety of information.

This study contributes theoretically to the Belief Adjustment Model based on the perspective of investors' investment decisions from a long sequence information series with several variations of information, and the type of order effect that occurs is not a primacy effect but a recency effect. Then, as a practical contribution to investors, this study can provide an idea that the sequence effect in the form of a recency effect can occur in investment decisions. In this case, investors need to pay attention to the information's substance provided by the company or information provider as a whole so that all information can be generalized and not only focus on newer information.

\section{Literature Review and Hypotheses Development}

Hogarth and Einhorn (1992) developed a Belief Adjustment Model, which explains the phenomenon that the order effect can arise from the interaction between information processing strategies and task characteristics. Belief adjustment classifies the effect of sequence phenomena on the task's characteristics that an individual receives, namely (1) the complexity of each item of evidence to be processed, (2) the length of the sequence of the number of pieces of information, (3) the response mode which is a procedure that asks individuals to express their beliefs.

In particular, Hogarth and Einhorn (1992) categorized each of these characteristics into two classes. First, complexity is divided into simple and complex information, which simply means that individuals' information only involves one information for each part, for example, properties of numbers. In this task, then individuals are assumed to be familiar with the task they receive. Meanwhile, complex individuals process large amounts of information on each piece of information/evidence, for example, each information contains 600 words, and the individual is assumed to be familiar or unfamiliar with the information. Second, the length of a series is grouped based on short or long information series. Short information series is classified into 2 to 12 parts of the information sequence, while long information series is categorized if the sequence of 
information is more than 17 parts. Finally, the response mode is divided into step-bystep and end-of-sequence procedures. For step-by-step procedures, individuals are asked to express their beliefs in each part. Each information/evidence is in a specific order. Meanwhile, at the end of the sequence, individuals will only report their beliefs after all the presented information. Pinsker (2007) then named this response mode the disclosure pattern, namely the sequential pattern for the step-by-step response mode and the simultaneous pattern for the end-sequence response mode. Types of occurrence of sequence effects based on the Belief Adjustment are presented in Table 1 below.

Table 1 Prediction of the occurrence of sequence effects based on the belief adjustment

\begin{tabular}{|c|c|c|c|c|}
\hline & \multicolumn{2}{|c|}{ Simple } & \multicolumn{2}{|c|}{ Complex } \\
\hline & End of Sequence & Step by Step & End of Sequence & Step by Step \\
\hline \multicolumn{5}{|c|}{ Mixed Information Set } \\
\hline Short & Primacy & Recency & Recency & Recency \\
\hline Long & Primacy & Primacy & Primacy & Primacy \\
\hline \multicolumn{5}{|c|}{ Consistent Information Set } \\
\hline Short & Primacy & No Effect & No Effect & No Effect \\
\hline Long & Primacy & Primacy & Primacy & Primacy \\
\hline
\end{tabular}

Source: Hogarth and Einhorn (1992, p. 17)

Hogarth and Einhorn (1992) described that when information has been accumulated, individual judgments will be less sensitive to the impact of newer information. On the other hand, when the direction of the information sequence changes in the opposite direction, the individual will be more sensitive to newer information. Hogarth and Einhorn (1992) named it a tendency toward more primacy or more recent information (recency). Thus, the differential tendency of information will result in primacy and recency in the information order effect.

Decision making is related to the process of thinking, managing, and solving problems (Siegel \& Ramanauskas-Marconi, 1989). When individuals want to make decisions, they will make judgments based on the information they get (Parker, Ferris, \& Otley, 1989). About considerations in evaluating the information obtained, an individual's decision should ideally be based on the value of the information's substance so that conclusions are made based on the information's substance (Alvia \& Sulistiwan, 2010). However, due to individuals' limitations in processing information systematically (such as Bazerman, 1994), individuals' decisions can be influenced by the order of the information itself (Alvia \& Sulistiawan, 2010).

Research on the effect of sequence on individual decisions has been of concern to many researchers. Some of them have proven that there is an order effect in the form of a recency effect when auditors evaluate short series information in making audit decisions (Cushing \& Ahlawat, 1996; Jensen, Lew, \& Chan, 1996; Bamber, Ramsay, \& Tubbs, 1997; Guiral \& Esteo, 2006; Sim, 2009). Then, several studies have also confirmed that the order effect in the form of recency effects is also found in management accountants (Dillard, Kauffman, \& Spires 1991), division heads (Trotman \& Wright, 1996), and investors (Alvia \& Sulistiwan, 2010; Almilia et al., 2013; Almilia \& Supriyadi, 2013; Hanafi, 
2017; Nisa, 2017) when they evaluate short series information. The findings in the short series of information support the Belief Adjustment's prediction (Hogarth \& Einhorn, 1992).

In contrast to research evaluating short series, studies examining a long series of information have predominantly not found an order effect as primacy affects individual decisions, as predicted by Belief Adjustment (Hogarth \& Einhorn, 1992). However, several studies have shown an order effect in the form of a recency effect when nonprofessional investors evaluate a long series of information (Daigle et al., 2015; Pinsker, 2011). Then, Rofiyah and Almilia (2017) found evidence that there is no order effect in investment decisions on the simultaneous presentation pattern when a long series of information is presented. In the same vein, Rafay and Farid (2018) emphasized that there is a primacy effect when investors evaluate shariah supervisory board reports simultaneously. It indicates that there is still inconsistency between individual theoretical perspectives and empirical evidence when individuals evaluate a long series of information, especially in terms of investment.

\section{The Direction of Information Sequence on Investment Decisions}

The Belief Adjustment Model (Hogarth \& Einhorn, 1992) implies that the final assessment update depends on the involvement of the form of information received by the individual, where there will be differences in individual judgment when the individual responds to mixed evidence involving positive and negative information. After the individual processes positive evidence of a person's adjustment level, which increases when the level is already high, it will cause negative evidence processed secondly to have a relatively more enormous impact.

Tuttle et al. (1997) found evidence that changes in market prices would be influenced by the arrival of the order of information so that positive information followed by negative information resulted in lower prices than negative information followed by positive information. Then, Pinsker (2011) examined non-professional investors' valuation changes based on a long series of information series. His research findings are consistent with the preliminary findings by Pinsker (2007), which exhibited that there was a greater decline in stock prices when investors received a collection of good news information followed by bad news than when investors received a collection of bad news information preceded or followed by a collection of good news. Based on this, Hypothesis 1 is presented as follows:

$\boldsymbol{H}_{1}$ : The investment decision of investors who accept the direction of negative to positive information sequence will be higher than the investors who accept the direction of positive to negative information sequence. 


\section{Patterns of Presenting Information on Investment Decisions}

The Belief Adjustment Model (Hogarth \& Einhorn, 1992) reveals two modes of response or procedures, in which individuals express their judgments, namely processing information sequentially and simultaneously. Cognitively, Hogarth and Einhorn (1992) imply that there is a possibility of individuals giving a higher assessment of sequential patterns than a simultaneous pattern. It is because individuals provide an assessment of each information so that they are more specific in giving a higher assessment than when all the information has been accumulated.

Almilia and Supriyadi (2013) examined the Belief Adjustment Model for investment decisions using accounting information proxies. Their findings are in agreement with those of Almilia et al. (2013), which implied bias in decisions if the information was presented sequentially compared to information presented simultaneously. Rofiyah and Almilia (2017) also found evidence that there was a higher assessment of investment decisions in presenting sequential information patterns than simultaneously on information with information proxies on corporate social responsibility and accounting (Pinsker, 2007). Besides, Pisnker (2011) showed concrete evidence that in a long series of non-professional investors' assessments, sequential patterns were higher than simultaneous proxies of voluntary information. Regarding this, Hypothesis 2 is presented as follows:

$\boldsymbol{H}_{2}:$ The investors' investment decisions who accept the sequential presentation pattern are higher than those who accept the simultaneous presentation pattern.

\section{Sequence Direction and Patterns of Presentation of Information on Investment Decisions}

The Belief Adjustment Model (Hogarth \& Einhorn, 1992) presents a prediction in which the occurrence of an order effect involving mixed evidence of positive to negative and negative to positive information directions is associated with sequential and simultaneous presentation pattern response modes. It indicates an interaction between the direction of information and the pattern of presenting information on judgments in an individual decision.

Pinsker $(2007 ; 2011)$ has proven the interaction between the direction and patterns of information presentation in changes to non-professional investors' valuations when evaluating accounting information. Pinsker (2007) concluded that in the direction of good news followed by bad news and in the direction of bad news followed by good news in a sequential presentation pattern has a much more substantial change in stock price valuation than those who receive information simultaneously. Pinsker stated that this effect occurs because disclosures contain conflicting information or what is called a contrast effect. Besides, Pinsker (2011) found evidence that the difference between the assessment of non-professional investors in the direction of the order of good news followed by bad news and bad news followed by bad news will be higher when investors 
accept the pattern of presenting financial information than those who accept the simultaneous information presentation pattern. Based on this, Hypothesis 3 is presented as follows:

$\boldsymbol{H}_{3}$ : The difference in investment decisions between investors who accept positive to negative and negative to positive order directions will be higher when the information is presented in a sequential pattern than in a simultaneous presentation pattern.

\section{Sequential Presentation Patterns with Negative to Positive and Positive to Negative Information Sequences on Investment Decisions}

The prediction of the order effect on the Belief Adjustment (Hogarth \& Einhorn, 1992) on a long series of information indicates that there will be no recency effect but the primacy effect, which is a primacy effect throughout a long series of information. However, from an investment perspective, Pinsker $(2007 ; 2011)$ reveals evidence that there is no primacy in non-professional investors' judgment. In particular, Pinsker has proven that from the results of the assessment of investor information, there is an order effect in the form of a recency effect. Likewise, Daigle et al. (2015) exposed evidence of primacy to change to recency in the final judgment of non-professional investors when voluntary information in a long series of information is presented in experimental stock markets. Moreover, Rofiyah and Almilia (2017) have confirmed the evidence that the order effect occurs when there is a mixture of positive to negative and negative to positive information direction in the sequential presentation pattern of long information series in the form of recency. It signifies that from an investment perspective, they will still be affected by the newer information when investors receive a long series of information sequentially.

Furthermore, the findings of the scope of investment in short information series, such as Alvia and Sulistiawan (2010), Almilia et al. (2013), Hanafi (2017), and Nisa (2017), found evidence that there is an order effect in the form of a recency effect occurring in investment decisions when individuals evaluate a mixture of positive followed by negative information or vice versa using a short series of information presented in a sequential pattern. It indicates that in the sequential pattern, individuals give a higher assessment of the direction of negative to positive information than individuals who receive positive to negative information so that investment decisions will be more influenced by newer information (recency). Regarding this, Hypothesis 4 is presented as follows:

$\boldsymbol{H}_{4}$ : When investors receive information in a sequential presentation pattern, the investment valuation will be higher in the direction of negative to positive information sequence than in the direction of positive to negative information sequence. 


\section{Simultaneous Presentation Patterns with Negative to Positive and Positive to Negative Information Sequences on Investment Decisions}

Hogarth and Einhorn (1992) suggest that simultaneous presentation patterns can reduce the contrast effect that individuals receive due to changing the direction of positive to negative or negative to positive evidence or information that contradicts the initial opinion. It is because the information presented can be gradually removed by combining all the evidence comprehensively. Almilia and Supriyadi (2013) and Almilia et al. (2013) verify that investors have no order effect in assessing the accounting information when the disclosure pattern is simultaneous. Likewise, Rofiyah and Almilia (2017) also uncovered no order effect with long information series when information is presented simultaneously in the direction of a mixture of positive to negative or negative to positive information on corporate social responsibility information. Further, Pinsker (2011) revealed evidence that information disclosure in the direction of a mixture of good news followed by bad and bad news followed by good news sequentially would lead to a more extensive assessment adjustment than simultaneous. It indicates that there is a low value in the simultaneous presentation pattern. In other words, nonprofessional investors will be affected by the effect of the order effect at a lower level if the information is presented in a simultaneous pattern so that this pattern can reduce the order effect of the information. Based on this, Hypothesis 5 is presented as follows:

$\boldsymbol{H}_{5}$ : When investors receive information in a simultaneous presentation pattern, there is no difference in investment appraisal between negative to positive information sequences and positive to negative information sequences.

\section{Research Method}

A controlled laboratory experiment was carried out to test the hypothesis using a $2 \times 2$ factorial design between subjects. The manipulation given to each group obtained two independent variables. First, the order direction, namely the information disclosure sequence, involved positive to negative and negative to positive news from the information. The direction of the sequence was manipulated on two levels (positive to negative or negative to positive). Second, the presentation pattern in the form of how the information frame was received by individuals. The presentation pattern was manipulated in 2 levels (sequential or simultaneous). Experiments were performed employing web-based instruments. Before experimenting, a series of pilot tests were conducted to verify the research instrument's validity and reliability requirements. The manipulations given to each group can be seen in Table 2 .

Table 2 Factorial Design of Experimental Manipulation

\begin{tabular}{|c|c|c|c|}
\hline \multirow[t]{2}{*}{ Sequence direction } & \multicolumn{3}{|c|}{ Information } \\
\hline & Patterns & Sequential & Simultaneous \\
\hline Positive- Negative & & Group 1 & Group 3 \\
\hline Negative-Positive & & Group 2 & Group 4 \\
\hline
\end{tabular}


The experimental task was modified from the instrument of Almilia et al. (2013) and Pinsker $(2007,2011)$, where participants took on the role of investors who were assessing company shares. The background and information regarding the company were conditioned by the researcher, according to the research needs. Participants evaluated information from a company called PT. Fully Fictitious Company, Tbk. This company was a fictitious company based on the mining industry with several business units. Then, participants were given a reference to the company's stock market price, namely Rp. 4,000 (four thousand rupiahs). This value would be stated as the company's stock market price during the early market opening session, which would serve as the initial anchor. Furthermore, participants were given 20 pieces of information. After that, participants were asked to re-evaluate the share price of the information provided by filling in the fields provided under the information column with multiples of 100 . Participants would determine how much the investment price per share of the company they recommended, for example, a multiple of 100 by giving a price share reduction of 100 (for instances, Rp. 3,900; or Rp. 3,800; ... or Rp. 3,000; Rp. 2,900; and so on) or giving an increase of +100 (for example Rp. 4,100; or Rp. 4,200; ... or Rp. 5,000; Rp. 5,100; and so on) with an initial price of Rp. 4,000. Information was designed so that the information's substance in the direction of positive information was the same as negative information or vice versa.

The experiment was carried out using a web-based facility, where participants were asked to visit a special interactive website prepared by the researchers. Before participants entered the website page, the researchers would send an invitation to each participant interested in the experiment. The invitation contained the experimental website address along with the username and password to access the page. All participants willing to participate were randomly assigned to one of the four experimental conditions. Participants would receive a username with different codes for randomization purposes. The username received by the participant would have access to one of the experimental conditions. Next, participants were asked to follow the experimental steps: (1) Approving the participant approval page, (2) Reading about the company's background, (3) Being given information regarding the initial stock price, (4) Re-evaluating the stock price from positive information (10 items) followed by negative information (10 items) or vice versa. The group with the sequential information presentation pattern manipulation would re-evaluate the value of the company's shares 20 times for each evidence provided. The simultaneous presentation pattern manipulation group would re-evaluate the company's share values one time from all the evidence. After the participants had finished evaluating the information provided, the participants were asked to (5) answer the risk tendency characteristics questions, (6) and the manipulation check questions, (7) then fill in the respondent's demographic information. Finally, (8) there would be a briefing, where participants would be notified of the experimental assignments they had done.

A manipulation check was carried out to determine whether the participants understood and answered correctly in the given case, first by determining the increase or decrease in the company's share price, which had to be a multiple of 100 . If the participant did not give a multiple of 100 , the participant was declared to have failed in 
the first manipulation. Participants who failed the manipulation check would be excluded from the research test.

The second manipulation check in the study was conducted by asking four questions about what they had done, for example, regarding the direction and pattern of presenting the information they received/evaluated. The participant had to answer all four manipulation questions correctly. These questions were given to assess the participants' understanding, attention, and seriousness in the experiment conducted.

This research's primary focuses were the direction of the order of information, the pattern of presenting information, and investment decisions. In this study, investment decisions refer to the stock price valuations that investors made when they evaluated the information. This investment decision was measured based on the overall magnitude of the share price assessment given from each manipulation of the direction and pattern of presenting the information provided, namely the initial value (anchor) (t0) to the final assessment (t20). Participants were asked to state how much their recommendation was to assess the shares' price in the company based on the information received by re-evaluating the value of the company's shares. Valuation measures in investment decisions were modified from Almilia and Almilia et al. (2013) and Pinsker (2011). The valuation in this investment decision was influenced by the order's direction and the pattern of information received. The information order direction involved positive to negative and negative to positive news from companyrelated information (Pinsker, 2011). For the manipulation of the direction of the information sequence, participants were given a different direction of information sequence; namely, some participants received positive to negative information directions, and some received negative to positive information directions. The pattern of presenting information is a form of information received and then responded to by participants (Hogarth \& Einhorn, 1992). For the manipulation of the pattern of presenting information, participants were given a different pattern of presenting information; some participants accepted a sequential pattern and the rest received a simultaneous pattern. The study's results from Kahneman and Tversky (1979), Weber, Blais, and Betz (2002), Gardner and Stainberg (2005), and Engelman and Tamir (2009) have proven that each individual has different risk preferences, and risk preferences can influence a person's decision. Therefore, this study used risk preference variables as covariates to influence individual judgment or decisions.

Charness, Gneezy, and Imas (2013) confirmed that the questionnaire is a method that can be used to generate risk preferences by relying on the individual's self-reported risk preference with general risk questions. Risk preference as a covariate in this study was measured using the financial domain by a questionnaire with a risk-perception scale of 1-5 points. This scaling technique was adopted from Weber et al. (2002), with participants assessing their perceptions of the risk posed by each risky behavior. It exhibited an in-depth assessment of each situation's risk on a 5-point rating scale, ranging from 1 indicating an improbable direction to engage in risky behavior to 5 indicating the most likely direction to be involved-risky behavior. 
Investors studied in this study were non-professional investors, with students as the projection. Student participants can be involved as proxies for non-professional investors with uncomplicated tasks (Elliott, Hodge, Kennedy, \& Pronk, 2007). Elliott et al. (2007) revealed that good proxies for non-professional investors are the business and financial accounting students. Accounting and finance students have also seen the role of investors in previous research (such as Almilia et al., 2013; Almilia \& Supriyadi, 2013; Daigle et al., 2015; Hanafi, 2017; Nisa, 2017; Pinsker, 2007, 2011; Rofiyah \& Almilia, 2017). Thus, the use of students as a surrogate in this study is acceptable.

Prospective participant data were obtained from the Indonesian Stock Exchange Investment Gallery's directory, Muhammadiyah Riau University. Then, participants had to have a stock portfolio account in a securities company or a Single Investor investor (SID). The criteria for participants who had a stock portfolio account or SID were directly involved in capital markets investment activities, such as the criteria in the research of Aprayuda and Misra (2020) and Gainau (2020). Data from participants who did not meet these requirements were excluded from the analysis. Manipulation checks were carried out by asking participants about their status following the subject in question and their SID/Account Portfolio.

This research provides control over risk preference factors as covariates that are thought to influence individual decisions, using the Analysis of Covariance (ANCOVA). For the first and second hypotheses, the main effect was tested by comparing stock price assessments made by participants based on the direction of the order of information and the pattern of presenting the information. The third hypothesis tested the interaction effect between the direction of the information sequence from positive to negative and negative to positive with sequential and simultaneous participant assessments' presentation patterns. Finally, to test the fourth and fifth hypotheses, the simple effect using the SPSS Syntax for ANCOVA was conducted to compare the share price assessments made by participants based on positive to negative information directions with negative to positive information directions in presenting sequential patterns and simultaneous patterns. Besides, this study would present the average participant assessment answers based on graphs. Recency occurred when the average group that received positive information followed by negative direction was smaller than the group that received negative information followed by positive on the information presentation pattern, and the form of assessment graphs from (t0) to (t20) formed a special fishtail pattern for sequential presentation patterns.

\section{Result and Discussion}

The demographic data of the 65 participants who participated in this study were classified by gender, age, and semester. Demographic data can be seen in Table 3. 
Does the Order of Information Affect Investors' Investment Decisions? Experimental Investigation

Table 3 Participants Demographic

\begin{tabular}{|c|c|c|c|}
\hline \multicolumn{2}{|c|}{ Participants Demographic } & Total & Percentage (\%) \\
\hline \multirow[t]{2}{*}{ Sex } & Mele & 19 & 29.2 \\
\hline & Female & 46 & 70.8 \\
\hline \multirow[t]{7}{*}{ Age } & 20 years old & 18 & 27.7 \\
\hline & 21 years old & 4 & 6.2 \\
\hline & 22 years old & 7 & 10.8 \\
\hline & 23 years old & 9 & 13.8 \\
\hline & 24 years old & 16 & 24.5 \\
\hline & 25 years old & 5 & 7.7 \\
\hline & 26 years old & 6 & 9.2 \\
\hline \multirow[t]{3}{*}{ Semester } & Semester 4 & 22 & 33.8 \\
\hline & Semester 6 & 19 & 29.2 \\
\hline & Semester 8 & 24 & 36.9 \\
\hline Total of Respondent & & 65 & 100 \\
\hline
\end{tabular}

The randomization test showed no difference in the participants' demographic characteristics between the experimental treatments. Table 4 presents the test results.

Table 4 Randomization Test Results

\begin{tabular}{clcccccc}
\hline \multicolumn{2}{c}{ Characteristics } & Sum of Squares & Df & Average Squared & F & Sig \\
\hline \multirow{2}{*}{ Type Genre } & Between Group & 1407442.080 & 1 & 1407442.080 & 1.614 & .209 \\
& Within Group & 54948557.92 & 63 & 872199.2332 & & \\
& Total & 54948557.92 & 64 & & & \\
\multirow{5}{*}{ Age } & Between Group & 4468394.841 & 6 & 744732.474 & .832 & .550 \\
& Within Group & 51887605.16 & 58 & 894613.882 & & \\
& Total & 56356000.00 & 64 & & & \\
\multirow{5}{*}{ Semester } & Between Groups & 308862.839 & 2 & 154431.419 & .171 & .843 \\
& Within Group & 56047137.16 & 62 & 903986.083 & & \\
\hline & Total & 56356000.00 & 64 & & & & \\
\hline
\end{tabular}

The manipulation check results between groups from the initial data were 77 participants, and 12 participants were eliminated because they failed to answer the manipulation check, as seen in Table 5.

Table 5 Manipulation Check Results

\begin{tabular}{|c|c|c|}
\hline \multicolumn{3}{|c|}{ Check Category Manipulation Direction of Positive to Negative Information Sequence } \\
\hline & $\begin{array}{l}\text { Sequential Information } \\
\text { Presentation Patterns } \\
\qquad(n=19)\end{array}$ & $\begin{array}{l}\text { Simultaneous } \\
\text { Information } \\
\text { Presentation Pattern } \\
(n=20)\end{array}$ \\
\hline $\begin{array}{l}\text { The number of participants who passed the } \\
\text { manipulation check }\end{array}$ & 15 & 18 \\
\hline \multirow[t]{2}{*}{ Percentage of correct responses } & $79 \%$ & $90 \%$ \\
\hline & $\begin{array}{l}\text { Sequential Information } \\
\text { Presentation Patterns } \\
\qquad(n=19)\end{array}$ & $\begin{array}{c}\text { Simultaneous } \\
\text { Presentation of } \\
\text { Information Patterns } \\
(n=19)\end{array}$ \\
\hline $\begin{array}{l}\text { The number of participants who passed the } \\
\text { manipulation check }\end{array}$ & 16 & 16 \\
\hline Percentage of correct responses & $84 \%$ & $84 \%$ \\
\hline
\end{tabular}


Risk preferences thought to influence investment decisions have been considered in this study as covariates, as seen in the ANCOVA model Table 6 . Hypothesis 1 predicts that the judgment of investors who accept negative to positive information sequence direction will be higher than investors who accept the direction of positive negative. This prediction implies a difference between the group receiving positive to negative information and the group receiving negative information to positive information, and their ratings are higher on positive information that becomes further information and lower on negative information that becomes later information. If there are these conditions, then there is an order effect in the form of a recency effect. Participants' responses are descriptively described in Table 6.

Table 6 Mean and Standard Deviation

\begin{tabular}{ccccc}
\hline \multirow{2}{*}{$\begin{array}{c}\text { Direction } \\
\text { Order }\end{array}$} & Pattern & \multicolumn{2}{c}{ Information Presentation Pattern } & Total Rows \\
Information & Sequential & Simultaneous & \\
Direction & & 2766,7 & 3716,6 & $3.241,6$ \\
& Negative & $(902,1)$ & $(718,5)$ & $(810,3)$ \\
& Positive & $\mathrm{n}=15$ & $\mathrm{n}=18$ & $\mathrm{n}=33$ \\
& & 4237,5 & 4262,5 & 4250 \\
\multicolumn{2}{c}{ Total Columns } & $(822,1)$ & $(485,6)$ & $(653,9)$ \\
& & $\mathrm{n}=16$ & $\mathrm{n}=16$ & $\mathrm{n}=32$ \\
& 3502,1 & 3989,6 & 3745,8 \\
& $(862,1)$ & $(602,1)$ & $(732.1)$ \\
& $\mathrm{n}=31$ & $\mathrm{n}=34$ & $\mathrm{n}=65$ \\
\hline
\end{tabular}

Table 7 Inter-Subject ANCOVA Test Results from Investment Decision Measures

\begin{tabular}{lrrrrr}
\hline & $\begin{array}{c}\text { Type III Sum of } \\
\text { the Squares }\end{array}$ & Df & $\begin{array}{c}\text { Average } \\
\text { Squared }\end{array}$ & F & Sig. \\
\hline Intersection & 20156325.91 & 1 & 20156325.91 & 38.761 & .000 \\
Risk Preference & 2632545.675 & 1 & 2632534.675 & 5.062 & .028 \\
Directions & 14419587.30 & 1 & 14419587.30 & 27.729 & .000 \\
Pattern & 4472490.129 & 1 & 4472490.129 & 8.601 & .005 \\
Direction * Pattern & 3820074.007 & 1 & 3820074.007 & 7.346 & .009 \\
Error & 31200787.66 & 60 & 520013.128 & & \\
Total & 975300000.0 & 65 & & & \\
Total corrected & 56356000.0 & 64 & & & \\
R Squared $=.446$ (Adjusted R Squared $=.409)$ & & & & \\
\hline
\end{tabular}

Table 7 descriptively shows the total average value of the share price appraisal by participants who received positive to negative information direction (average $=3241.6$ rupiahs) than negative to positive information (average $=4250$ rupiahs). As seen in the ANCOVA model presented in Table 6, there was a significant difference in investment decisions between the information order's direction $(F=27,729, p=0.000)$. These findings indicated an order effect on investors' decisions. Besides, the average value of the direction of negative to positive information was higher than the direction of positive to negative information. This value indicated that there was recency in the participant's assessment. These findings supported Hypothesis $1\left(\mathrm{H}_{1}\right)$. 
Furthermore, as seen in Table 6, investors who received the financial information pattern gave an average share price valuation of 3502.1 rupiahs, while investors who accepted the simultaneous pattern gave an average share price valuation of 3989.6 rupiahs. The ANCOVA model in Table 7 exhibits a significant difference in investment decisions between presenting information patterns $(F=27,729, p=0.000)$. However, because the average assessment of investors who accepted sequential patterns was not higher than investors who accepted simultaneous patterns, this finding did not support Hypothesis $2\left(\mathrm{H}_{2}\right)$.

Hypothesis 3 predicts that the difference in valuation between investors who accept positive to negative and negative to positive order directions will be higher when the information is presented in a sequential presentation pattern rather than a simultaneous presentation pattern. Table 6 descriptively shows that the difference in investor judgment between the direction of positive to negative and negative to positive information in the sequential presentation pattern was higher $(2766.7-4237.5=1470.8$ rupiahs) than in the simultaneous presentation pattern $(4262,5-3716.6=545.9$ rupiahs). This difference is displayed in Table 7 as a significant interaction effect between the direction of the sequence and the pattern of presenting information $(F=$ $7,346 \mathrm{p}=0.09)$. These findings supported Hypothesis $3\left(\mathrm{H}_{3}\right)$. Since the results of Hypothesis 3 indicated a significant interaction effect on the two combinations of independent variables, testing for Hypotheses 4 and 5 could be continued. Testing Hypothesis 4 and Hypothesis 5 aimed to see if there were differences in investment appraisal given by investors who accepted the direction of the positive to negative information sequence and investors who were given the direction of the negative to positive information sequence when they accepted specific patterns of presenting information (information presented in a sequential pattern or a simultaneous pattern). Descriptive statistics of the direction and pattern interaction testing can be seen in the Table 8.

Table 8 Univariate Test Results on Direction * Pattern

\begin{tabular}{llrrrrr}
\hline \multicolumn{2}{c}{ Pattern } & Sum of Squares & Df & Average Squared & F & Sig. \\
\hline Sequential & Contrast & 16001178.283 & 1 & 16001178.283 & 30.771 & .000 \\
& Error & 31200787.662 & 60 & 520013.128 & & \\
Simultaneous & Contrast & 1803569.949 & 1 & 1803569.949 & 3.468 & .067 \\
& Error & 31200787.662 & 60 & 520013.128 & & \\
\hline
\end{tabular}

Hypothesis 4 predicts that when investors receive information in a sequential presentation pattern, the investment valuation will be higher in the direction of negative to positive information order than in the direction of positive to negative information order. This prediction implies that when investors are faced with a pattern of presenting sequential information, they will be affected by order of the information. It can be seen from Table 6 that there was a significant difference in the assessment between investors who accepted the direction of the positive to negative information sequence and the direction of the negative to positive information sequence in the sequential presentation pattern $(F=30,771, p=0.000)$. These findings suggested an order effect occurred in investors' decisions when they evaluated information sequentially. This finding supported Hypothesis 4. At the same time, the aggregate share price valuation 
given by investors in each manipulation group can be seen in Figure 1, which describes the sequential effect in the form of recency effects occurring in investors' decisions when they accepted the pattern of presenting sequential information.

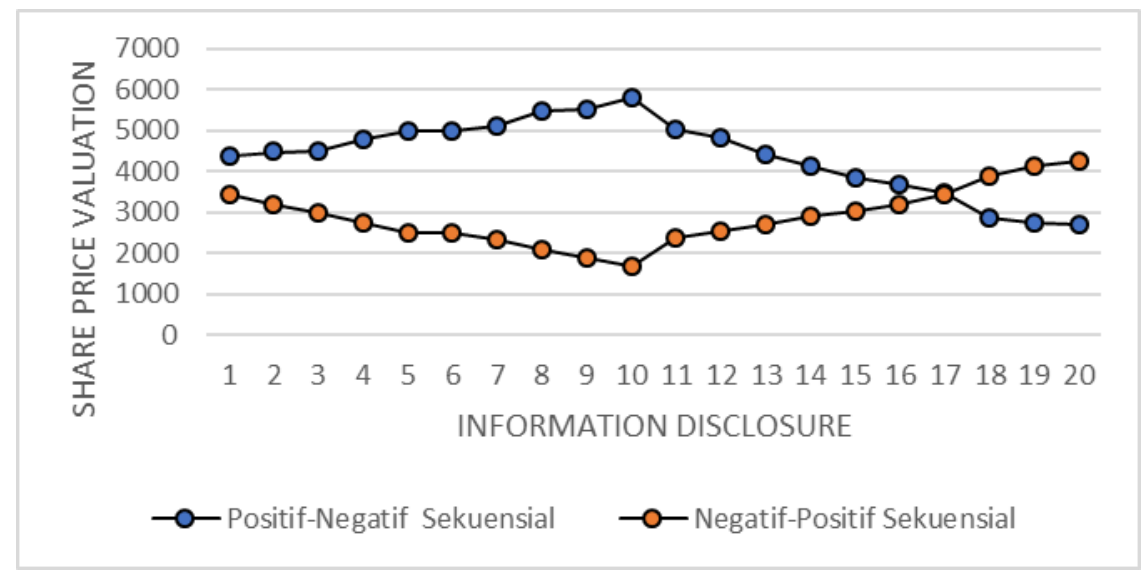

Figure 1 Average Share Price for 20 Information Disclosures

The shape of the image in Figure 1 shows an indication of the recency effect, such as Hogarth and Einhorn (1992). Pinsker (2011) named this chart pattern the "fishtail" effect. As in Figure 1, showing the form of a "fishtail" pattern for sequential presentation manipulation, this picture reinforces the statement that a sequential effect occurred in the form of a recency effect in investors' decisions.

Hypothesis 5 predicts that when investors receive information in a simultaneous presentation pattern, there is no difference in investment appraisal between negative to positive information sequences and positive to negative information sequences. This prediction implies that when investors are faced with a pattern of simultaneous presentation of the information, they will not be affected by order of information. It can be seen from Table 6 that there was no difference in the assessment between investors who accepted the direction of the positive to negative information sequence and the direction of the negative to positive information sequence in the simultaneous presentation pattern $(F=3.468, p=0.067)$. These findings indicated no order effect on investors' decisions when they evaluated the information simultaneously. Therefore, this study's findings supported Hypothesis 5.

Belief adjustment (Hogarth \& Einhorn, 1992) implies an order effect when individuals process a sequence of information. Based on the research findings presented earlier, the presence of an order effect in investors' investment decisions was indicated by the difference between groups of investors who accepted the direction of positive to negative and negative to positive information sequences. Then, the group of investors who accepted the negative to positive direction gave a higher rating than the positive to the negative group or vice versa. On average, it indicated that the latest information was the main focus of investors. In other words, there was a recency effect in their assessment. It was because individual investors prioritized newer information that they found when they evaluated information. After all, they consider new information more 
relevant to their decisions, as stated by Pinsker (2007), especially if the direction of the information is negative, which leads to positive information; or otherwise, disclosed information close to each other systematically, as argued by Graham et al. (2005).

This study's findings confirm that investors are susceptible to order effects when they evaluate information when evaluating information in their decisions (Tuttle et al., 1997). This study's findings provide support for Pinsker's (2007) research, which states that there is a change in valuation of non-professional investors so that they are affected by the order when evaluating the direction of the mix of good news followed by bad news and bad news followed by good news. Furthermore, this study's findings reinforce the findings from Pinsker (2011) and Diagle et al. (2015), which uncovered that investors are more affected by the final information they receive in their decisions, resulting in a sequential effect in the form of a recency effect on investors when they evaluate mixed order direction information for voluntary information in a long series.

Hogarth and Einhorn (1992) imply that cognitively, there is a possibility that individuals give higher ratings of sequential patterns than simultaneously. It is because individuals provide an assessment of each information so that they are more specific in giving higher ratings than when they have obtained all the accumulated evidence. However, this study's findings indicate that the average number of investors who accepted the sequential presentation pattern was not higher than the investors who accepted the simultaneous pattern. Hogarth and Einhorn (1992) have described the possibility that this can happen; even though individuals receive a simultaneous information pattern response mode, the decision-maker may still make judgments with a sequential pattern response mode, or part-by-part, to reduce cognitive stress due to variations in the information be accepted.

Besides, this finding is different from Pinker's (2011) findings, who found that the total valuation of investors who accepted a sequential pattern was higher than that of simultaneously. Researchers argue that it occurred because of differences in the proxies of information used. This study employed a mixture of financial information, corporate governance, and the industrial sector. It is different from the research by Pinsker (2011), which only used voluntary information. Holm and Rikhardsson (2008) provide evidence that when investors receive a mix of variations in financial information and environmental information, it will affect their investment allocation. Therefore, based on this study's findings, when investors received information with more varied variations simultaneously, they gave a higher allocation of ratings at the end of their assessment at the end of the session according to the final information's direction.

Based on the findings previously described, this study confirms the interaction between the direction of the order and the presentation pattern on individual decisions according to the Belief Adjustment Model (Hogarth \& Einhorn, 1992). When investors receive information that contradicts the information they received initially, such as positive information followed by negative or negative followed by positive, then decision-makers will be more sensitive to newer information. In other words, they are more sensitive to information that contradicts the previous one, especially if they receive the information 
in sequential-systematic order. Investors can give a higher valuation on the sequential presentation of information because the sequential presentation response mode provides investors with more opportunities to make adjustments than the simultaneous presentation pattern. Therefore, they provide excessive information in the sequential pattern when the direction of the sequence of information is positive to negative or negative to positive so that the difference in sequential presentation patterns is higher than the simultaneous presentation pattern, which only provides an overall assessment. This research is in line with Pinsker's (2011) findings, which proves an interaction between the direction and patterns of information presentation in changes in nonprofessional investors' assessment. Besides, this study supports the results of Pinsker (2011) that the difference in stock price differences in the direction of good news followed by bad news and bad news followed by good news was higher when nonprofessional investors accepted the pattern of presenting financial information than non-professional investors who accepted the pattern of presenting information simultaneously.

Belief adjustment (Hogarth \& Einhorn, 1992) reveals an order effect when positive mixed information is followed by negative information or negative information followed by positive presented in a sequential pattern. Previous findings suggest that order effects occur in investors' decisions when they evaluate information sequentially. Then, in this pattern, their rating is higher in the direction of the negative to positive information sequence than in the direction of the positive to the negative sequence. Therefore, it can be concluded that investors as users of information from companies or their information providers will be more sensitive in responding to newer information (recency effect), so they tend to be biased in making judgments. It is also seen in the shape of the "fishtail" pattern, which indicates recency.

This finding confirms the belief adjustment (Hogarth \& Einhorn, 1992), which states that an order effect occurs in individual decisions. However, the type of sequential effect that occurs in this study rejects predictions based on the belief adjustment model. It suggests that when an individual accepts the direction of a mixture of negative and positive information in a long series sequential presentation pattern, the individual will be less sensitive to the impact of newer information or later information, resulting in an effective sequence of primacy effects.

This study's findings indicate that there were no signs that primacy phenomena occurred in long information chains. On the other hand, these findings indicate that the latest information was the main focus of investors; in other words, there was a recency effect. The findings of this study are consistent with previous findings that examined investment in short information series, such as Alvia and Sulistiawan (2010), Almilia and Supriyadi (2013), Hanafi (2017), Almilia et al. (2013), and Nisa (2017), stating that there was an order effect in the form of recency when the direction of information was mixed with a sequential pattern. However, the short series of information that has been studied reveals support for recency prediction based on the belief adjustment model. Therefore, this study's findings further verify the findings in a long series of information 
because based on the test results, this study's findings reject the prediction of primacy from the belief adjustment model.

This study provides support for research conducted by Pinsker (2007). Pinsker stated that there are changes in non-professional investors' valuation when evaluating mixed direction information on sequential information presentation patterns for accounting information. Furthermore, the findings of this study confirm the findings of Pinsker (2011), Diagle et al. (2015), and Rofiyah and Almilia (2017), which found that the order effect in the form of a recency effect occurred on investors when they evaluated mixed direction information on the pattern of presenting sequential information for voluntary information.

The findings previously described did not indicate the occurrence of an order effect when investors evaluate information simultaneously. It showed that if the information were presented comprehensively, investors would provide a more objective assessment. Even though the information was displayed in a different order from the simultaneous presentation pattern, investors could generalize all information because the information was presented comprehensively. These findings confirm Hogarth and Einhorn's (1992) opinion, which implies that simultaneous presentation patterns can reduce the effect of contrast on information direction. Then, this study's findings corroborate Almilia and Supriyadi's (2013) findings, indicating that simultaneous presentation patterns can be used to eliminate the information order effect when investors evaluate the information in their decisions. Furthermore, this finding is in line with Almilia et al.'s (2013) findings, which stated that there was no difference in the final assessment when the direction of the information order was positive to negative or negative to positive in the simultaneous presentation pattern of accounting and non-accounting information. This result is also consistent with Rofiyah and Almilia's (2017) findings, which uncovered that there was no order effect in investment decisions when the information was presented in a simultaneous pattern in the direction of long series information mixed information series on corporate social responsibility information.

Besides, these findings differ from Pinsker $(2007,2011)$, who found an order effect between the direction of the mix of good news and bad news information in a simultaneous pattern. Specifically, their findings implied that if the information was presented simultaneously, the order effect was at a lower level, so that their findings suggest that the simultaneous presentation pattern can reduce the order effect of the information. Thus, these findings are consistent with Pinsker's findings. On the other hand, these findings contrast with the findings of Rafay and Farid (2018), which stated that there was a sequential effect in the form of a primacy effect when investors evaluated information. It happened because they saw a perspective from a sharia banking perspective and focused on the Shariah Supervisory Board elements that were different from the perspective of this study, presenting conventional financial and nonfinancial reporting instruments. There are also differences in the characteristics of the objectives and equity asset allocation strategies between sharia and conventional (Umar, 2017). 


\section{Conclusion}

This study examines the effect of the order of information in making investment decisions based on the direction of the order and the pattern of presenting the information. This study's results confirm the order effect according to belief adjustment. There was a difference in valuation between investors who accepted the direction of positive to negative and negative to positive information sequences so that it could be denoted that investors were affected by the information order when they evaluated the information in an investment decision. Based on the findings, investors gave a higher assessment of more recent information. Alternatively, it could be concluded that their decisions were influenced by later information so that the order effect occurred in the form of recency. It suggested that investors were affected by the information order effect and only focused on newer information, which biased their judgment, thereby affecting the quality of investment decisions. On the other hand, while previous research has considered the final judgment to be higher if the information was presented sequentially, this study's findings provide a different view, where the valuation was higher if investors evaluated the information presented simultaneously across many types of information variations in a long series.

However, the type of order effect that occurred in this study rejected the prediction of primacy effects according to the belief adjustment model. Based on the findings, there were no signs that the primacy effect phenomenon occurred in all experimental groups in the long information series. Besides, the findings did not reveal any difference in investors' investment appraisals if the information was presented simultaneously in the direction of mixed positive to negative or negative to positive information. Therefore, these findings provide a perspective that the simultaneous pattern could reduce the contrast of the order of information so that investors could generalize all information because the information presented comprehensively even though the information was displayed in a different order. This study's findings underline the importance of investors paying attention to the information's substance provided by the company or information provider as a whole so that all information can be generalized, and not only focusing on newer information disclosure. It is because, in practice, the information available in the capital market will be in the direction of the particular direction patterns so that the user is potentially subject to bias from the sequence of information itself.

This study has some limitations. First, the participants who joined this research had already been involved in investing in stocks in the capital market, but it did not mean that they were investors with comprehensive experience. Future research may be necessary to prove the order effect on individual investors with experiences in the stock market, such as securities firm practitioners or set investment horizon limits on individual portfolios. Finally, the information provided to participants was limited to the type of financial, governance, and industry sectoral information. In practical terms, investors may be exposed to much more complex information. Research efforts in the future can present a variety of other information used by investors in making decisions, such as technical analysis, forecast management or brokers, and so on that have not been considered. 


\section{References}

Alattar, J. M., \& Al-Khater, K. (2007). An empirical investigation of users' views on corporate annual reports in Qatar. International Journal of Commerce and Management, 17(4), 312-325. https:// doi.org/10.1108/10569210710844381

Almilia, L. S., \& Supriyadi. (2013). Examining belief-adjustment model on investment decision making. International Journal of Economics and Accounting, 4(2), 169-183. https://doi.org/10.1504/IJEA.2013.055171

Almilia, L. S., Hartono, J., Supriyadi, S., \& Nahartyo, E. (2013). Examining the effects of presentation patterns, orders, and information types in investment decision making. Gadjah Mada In International Journal of Business, 15(2), 171-182. https://doi.org/10.22146/gamaijb.5701

Alvia, L., \& Sulistiawan, S. (2010). The examination of recency and knowledge effect in investment decision making: An experimental study. Indonesian Journal of Accounting Research, 13(1), 45-58. http://doi.org/10.33312/ijar.217

Aprayuda, R., \& Misra, F.(2020) Faktor-faktor yang mempengaruhi keinginan investasi investor muda di pasar modal Indonesia. E-Jurnal Akuntansi Universitas Udayana, 30(5), 1084-1098. https://doi.org/10.24843/eja.2020.v30.i05.p02

Bamber, E. M., Ramsay, R. J., \& Tubbs, R. M. (1997). An examination of the descriptive validity of the belief-adjustment model and alternative attitudes to evidence in auditing. Accounting, Organizations and Society, 22(3-4), 249-268. https://doi.org/10.1016/s0361-3682(96)00029-3

Bazerman, M. H., Giuliano, T., \& Appelman, A. (1984). Escalation of commitment in individual and group decision making. Organizational Behavior and Human Performance, 33(2), 141-152. https://doi.org/10.1016/0030-5073(84)90017-5

Bazerman, M.H. (1994). Judgment in Managerial Decision Making. Willey \& Sons. Inc.

Charness, G., Gneezy, U., \& Imas, A. (2013). Experimental methods: Eliciting risk preferences. Journal of Economic Behavior \& Organization, 87, 43-51. https://doi.org/10.1016/j.jebo.2012.12.023

Cushing, B. E., \& Ahlawat, S. (1996). Mitigation of recency bias in audit judgment: the effect of documentation. Auditing: A Journal of Practice and Theory, 15(1), 110-122. Retrieved from https://www.econbiz.de/Record/mitigation-of-recency-bias-in-auditjudgment-the-effect-of-documentation-cushing-barry/10007003584

Daigle, R. J., Pinsker, R., \& Pitre, T. J. (2015). The impact of order effects on nonprofessional investors' belief revision when presented a long series of disclosures in an experimental market setting. Accounting Horizons, 29(2), 313-326. https://doi.org/10.2308/acch-50997

Deegan, C., \& Rankin, M. (1997). The materiality of environmental information to users of annual reports. Accounting, Auditing \& Accountability Journal, 10(4), 562-583. https://doi.org/10.1108/09513579710367485

Dillard, J. F., Kauffman, N. L., \& Spires, E. E. (1991). Evidence order and belief revision in management accounting decisions. Accounting, Organizations and Society, 16(7), 619633. https://doi.org/10.1016/0361-3682(91)90016-8

Elliott, W. B., Hodge, F. D., Kennedy, J. J., \& Pronk, M. (2007). Are M.B.A. students a good proxy for nonprofessional investors? The Accounting Review, 82(1), 139-168. https://doi.org/10.2308/accr.2007.82.1.139

Gainau, P. C. (2020). Have Students Comprehended Investment?. Journal of Accounting and Investment, 21(3), 514-536. https://doi.org/10.18196/jai.2103162 
Gardner, M., \& Steinberg, L. (2005). Peer influence on risk taking, risk preference, and risky decision making in adolescence and adulthood: An experimental study. Developmental Psychology, 41(4), 625-635. https://doi.org/10.1037/0012-1649.41.4.625

Graham, J. R., Harvey, C. R., \& Rajgopal, S. (2005). The economic implications of corporate financial reporting. Journal of Accounting and Economics, 40(1-3), 3-73. https://doi.org/10.1016/i.jacceco.2005.01.002

Guiral, A., \& Esteo, F. (2006). Are Spanish auditors skeptical in going concern evaluations? Managerial Auditing Journal, 21(6), 598-620. https://doi.org/10.1108/02686900610674889

Hanafi, T. (2017). The testing of belief-adjustment model and framing effect on nonprofessional investor's investment decision making. The Indonesian Accounting Review, 7(1), 1-14. https://doi.org/10.14414/tiar.v7i1.945

Hogarth, M. R., \& Einhorn, H. (1992). Order effects in belief updating: The beliefadjustment model. Cognitive Psychology, 24(1), 1-55. https://doi.org/10.1016/0010$\underline{0285(92) 90002-j}$

Holm, C., \& Rikhardsson, P. (2008). Experienced and novice investors: Does environmental information influence investment allocation decisions? European Accounting Review, 17(3), 537-557. https://doi.org/10.1080/09638180802016627

Jensen, H. L., Lew, A. Y., \& Chan, M. M. K. (1996). Order effects and the extent of substantive testing. Managerial Auditing Journal, 11(7), 21-27. https://doi.org/10.1108/02686909610131837.

Nisa, A. K. (2017). Belief adjustment model test in investment decision making: Experimentation of short information series. The Indonesian Accounting Review, 7(1), 15-30. https://doi.org/10.14414/tiar.v7i1.943

Parker, L. D. , Ferris, K. R., \& Otley, D. T. (1989). Accounting for the buman factor. Prentice Hall: Englewood Cliffs, N.J

Pinsker, R. (2007). Long series of information and nonprofessional investors' belief revision. Behavioral Research In Accounting, 19(19), 197-214. https://doi.org/10.2308/bria.2007.19.1.197

Pinsker, R. (2011). Primacy or recency? A study of order effects when nonprofessional investors are provided a long series of disclosures. Behavioral Research In Accounting, 23(1), 161-183. https://doi.org/10.2308/bria.2011.23.1.161

Rafay, A., \& Farid, S. (2018). Shariah Supervisory Board Report (SSBR) in Islamic banks. International Journal of Islamic and Middle Eastern Finance and Management, 11(2), 274-296. https://doi.org/10.1108/IMEFM-07-2017-0180

Rofiyah, F. D., \& Almilia, L. S. (2017). Testing the effect of belief adjustment model and overconfidence on investment decision making. The Indonesian Accounting Review, 7(2), 177-190. https://doi.org/10.14414/tiar.v7i2.952

Siegel, G. \& Ramanauskas-Marconi, H. (1989). Behavioral accounting. South-Western Publishing Co.

Sim, M. (2009). National culture effects on groups evaluating internal control. Managerial Auditing Journal, 25(1), 53-78. https://doi.org/10.1108/-02686901011007306

Sofyan, R., Putra, D. G., \& Aprayuda, R. (2020). Does the information on the internet media respond to the stock market? Proceedings of the 5 th Padang International Conference On Economics Education, Economics, Business and Management, Accounting and Entrepreneurship (PICEEBA-5 2020), 510-520. https://dx.doi.org/10.2991/aebmr.k.201126.057

Trotman, K.T., \& Wright, A. (1996). Recency Effects: Task complexity, decision mode, and task-specific experience. Behavioral Research in Accounting, 8(1), 175-193. Retrieved from https://www.scopus.com/record/display.uri?eid=2-s2.0-

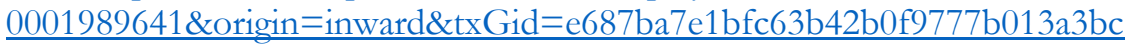


Tuttle, B., Coller, M., \& Burton, F. G. (1997). An examination of market efficiency: Information order effects in a laboratory market. Accounting, Organizations and Society, 22(1), 89-103. https://doi.org/10.1016/s0361-3682(96)00026-8

Tversky, A. \& Kahneman, D. (1973), Availability: a heuristic for judging frequency and probability. Cognitive Psychology, 5(2), 207-232. https://doi.org/10.1016/0010$\underline{0285(73) 90033-9}$

Umar, Z. (2017). Islamic vs conventional equities in a strategic asset allocation framework. Pacific-Basin Finance Journal, 42(1), 1-10. https://doi.org/10.1016/j.pacfin.2015 .10 .006

Weber, E. U., Blais, A.-R., \& Betz, N. E. (2002). A domain-specific risk-attitude scale: Measuring risk perceptions and risk behaviors. Journal of Behavioral Decision Making, 15(4), 263-290. https://doi.org/10.1002/bdm.414 